\title{
Multiple exportins influence thyroid hormone receptor localization
}

\author{
Kelly S. Subramanian ${ }^{\mathrm{a}}$, Rose C. Dziedzic ${ }^{\mathrm{a}}$, Hallie N. Nelson ${ }^{\mathrm{a}}$, Mary E. Stern ${ }^{\mathrm{a}}$, Vincent R. Roggero ${ }^{\mathrm{a}}$, \\ Cornelius Bondzi ${ }^{\mathrm{b}}$, Lizabeth A. Allison ${ }^{\mathrm{a} *}$ \\ ${ }^{a}$ Department of Biology, College of William and Mary, Williamsburg, Virginia 23185, USA \\ ${ }^{\mathrm{b}}$ Department of Biological Sciences, Hampton University, Hampton, Virginia 23668, USA \\ *Corresponding author. Department of Biology, College of William and Mary, 540 Landrum Dr., ISC \\ 2117, Williamsburg, Virginia 23185, USA. Tel.: +1 757 221-2232; fax: +1 757 221-6483; E-mail \\ address: laalli@wm.edu (L. A. Allison)
}

\begin{abstract}
The thyroid hormone receptor (TR) undergoes nucleocytoplasmic shuttling and regulates target genes involved in metabolism and development. Previously, we showed that TR follows a CRM1/calreticulinmediated nuclear export pathway. However, two lines of evidence suggest TR also follows another pathway: export is only partially blocked by leptomycin B (LMB), a CRM1-specific inhibitor; and we identified nuclear export signals in TR that are LMB-resistant. To determine whether other exportins are involved in TR shuttling, we used RNA interference and fluorescence recovery after photobleaching shuttling assays in transfected cells. Knockdown of exportins 4, 5, and 7 altered TR shuttling dynamics, and when exportins 5 and 7 were overexpressed, TR distribution shifted towards the cytosol. To further assess the effects of exportin overexpression, we examined transactivation of a TR-responsive reporter gene. Our data indicate that multiple exportins influence TR localization, highlighting a fine balance of nuclear import, retention, and export that modulates TR function.
\end{abstract}

Key words: thyroid hormone receptor, thyroid hormone, nuclear export, exportin

\section{Introduction}

Thyroid hormone (triiodothyronine, $\left.\mathrm{T}_{3}\right)^{1}$ is important in regulating genes responsible for metabolism, growth, and development. Encoded by two different genes, thyroid hormone receptors TR $\alpha 1$ and TR $\beta 1$ respond to $\mathrm{T}_{3}$ levels by activating or repressing target gene expression. Although primarily found in the nucleus at steady-state, TR $\alpha 1$ and TR $\beta 1$ can rapidly shuttle between the nucleus and cytoplasm (Baumann et al., 2001; Bunn et al., 2001; Grespin et al., 2008). Nuclear import and export of proteins occurs through the nuclear pore complexes, mediated by members of the karyopherin $\beta$ family called importins and exportins, respectively (Kimura and Imamoto, 2014; Pemberton and Paschal, 2005). By coupling mutagenesis and localization studies, nuclear localization signal (NLS) and nuclear export signal (NES) motifs that interact with the transport machinery have been found in conserved domains of members of the nuclear receptor superfamily (Black et al., 2004; Holaska et al., 2002; Kanno et al., 2007; Kanno et al., 2005; Liu and DeFranco, 2000; Lombardi et al., 2008; Mavinakere et al., 2012; Nguyen et al., 2009; Pemberton and Paschal, 2005; Picard and Yamamoto, 1987; Saporita et al., 2003; Sorokin et al., 2007;

${ }^{1}$ The abbreviations used are: $\mathrm{T}_{3}$, thyroid hormone (triiodothyronine); TR $\alpha 1$, thyroid hormone receptor $\alpha 1$; TR $\beta 1$, thyroid hormone receptor $\beta 1$; NLS, nuclear localization signal; NES, nuclear export signal; CRM1, chromosome region maintenance 1; leptomycin B, LMB; FRAP, fluorescence recovery after photobleaching; RNAi, RNA interference; GFP, green fluorescent protein; shRNA, short hairpin RNA; qPCR, quantitative PCR; TRE, thyroid hormone response element; WGA, wheat germ agglutinin; microRNA (miRNA). 
Umemoto and Fujiki, 2012). This transport process provides a central regulatory point for coordinating cell signaling and gene expression.

From our prior studies, an increasingly complex picture has emerged of the intricate molecular mechanisms that regulate trafficking and function of TR $\alpha 1$ and TR $\beta 1$ (collectively referred to as TR hereinafter for simplicity). Previously, we showed that TR can exit the nucleus by a pathway mediated by the export factor CRM1 (chromosome region maintenance 1), also known as exportin 1, in cooperation with calreticulin (Grespin et al., 2008); however, the exact interaction and mechanism remain unclear. Two main lines of evidence suggested that TR might also follow a CRM1/calreticulin-independent nuclear export pathway. First, under conditions in which TR still shuttles, shuttling of p53 and the oncoprotein v-ErbA is completely blocked in the presence of the CRM1-specific inhibitor leptomycin B (LMB) (Bunn et al., 2001; DeLong et al., 2004). Also, during fluorescence recovery after photobleaching (FRAP) experiments, when one nucleus in a multinucleate HeLa cell was photobleached, recovery of fluorescence in the bleached nucleus in the presence of LMB was reduced by only $60 \%$, relative to recovery in the absence of LMB (Grespin et al., 2008). Second, no CRM1-dependent NES in TR has yet been characterized (Mavinakere et al., 2012). Indeed, our studies showed that TR interacts directly with calreticulin but complex formation with CRM1 was not detectable in pull-down assays (Grespin et al., 2008). In an effort to identify and clarify the mode of TR nuclear export, we previously carried out a comprehensive analysis of TR to screen for NES motifs. We identified a region spanning helices 3 and 6 of the ligand-binding domain, that either houses two monopartite NESs or a single, bipartite NES, and we fully characterized another NES in helix 12 of the ligand-binding domain. These NES motifs were able to export a nucleus-localized fusion protein to the cytosol (Mavinakere et al., 2012). Intriguingly, these NES motifs were shown to be insensitive to LMB. In the presence of LMB, they were still able to direct the fusion protein to the cytosol, suggesting that they follow a CRM1-independent export pathway (Mavinakere et al., 2012).

In the present study, we sought to determine whether other exportins are involved in this alternative nuclear export pathway of TR, and to determine their relative contributions to TR export overall. To this end, we coupled RNA interference (RNAi) with FRAP experiments in live HeLa cells. Shuttling dynamics of TR were assessed upon knockdown of transportins 1 and 2, and exportins, 4, 5, 6, and 7. Additionally, we used overexpression assays and $\mathrm{T}_{3}$-responsive reporter gene assays to further assess the role of a panel of exportins in modulating TR function. Exportin-t and exportin 2 (CAS/CSE1L) were not included in our study, since they are specific for tRNA export (Arts et al., 1998) and importin $\alpha$ export (Kutay et al., 1997), respectively. We also excluded RanBP17; although a close homolog of exportin 7 (RanBP16), it is primarily expressed in the testis and pancreas, and a direct role for this protein in nuclear export has not been demonstrated (Koch et al., 2000; Kutay et al., 2000). Taken together, results presented here provide evidence that multiple exportins influence cellular localization of TR $\alpha 1$ and TR $\beta 1$ and, in this way, may play a role in modulating $\mathrm{T}_{3}$-mediated gene expression.

\section{Methods}

\subsection{Plasmids}

The plasmid pGFP-TR $\alpha 1$ encodes a functional green fluorescent protein (GFP)-tagged rat TR $\alpha 1$ fusion protein (Bunn et al., 2001). pGFP-TR $\beta 1$ encodes a functional GFP-tagged human TR $\beta 1$ (Mavinakere et al., 2012). Pre-designed SureSilencing ${ }^{\mathrm{TM}}$ short hairpin RNA (shRNA) plasmid sets consisting of four different shRNA expression plasmids for each target mRNA were purchased from SABioscience (Frederick, MD) for human transportin 1 (TNPO1), transportin 2 (TNPO2), exportin 4 (XPO4), exportin 5 (XPO5), exportin 6 (XPO6), exportin 7 (XPO7), and a scrambled sequence negative control. pk-Myc-exportin 5, pCMV-Myc, and pCMV-HA were obtained from Addgene (Cambridge, MA), Clontech Laboratories, Inc. (Mountain View, CA), and BD Biosciences (San Jose, CA), respectively. The HA-tagged exportin 7 expression plasmid (pMT2SM-RanBP16) was a gift from C. 
Smas (University of Toledo College of Medicine, Ohio). The mCherry-tagged exportin 4 expression plasmid (pmCherry-XPO4) was obtained from GenScript (Piscataway, NJ) and pmCherry-C1 was from Clontech. 2xDR4-SV40-Luc was a gift from J. L. Jameson, (Northwestern University) and consists of two copies of a positive, direct repeat TRE $(\mathrm{DR}+4)$ in the firefly luciferase vector pGL3. pGL4.74 encodes Renilla luciferase (Promega, Madison, WI).

\subsection{Fluorescence recovery after photobleaching (FRAP)}

HeLa cells (ATCC, \#CCL-2) were cultured in Minimum Essential Medium (MEM) supplemented with $10 \%$ fetal bovine serum (Life Technologies, Grand Island, NY), at $37^{\circ} \mathrm{C}$ under $5 \% \mathrm{CO}_{2}$ and $98 \%$ humidity. Cells were seeded at 2.0-2.5 x 105 cells per $3-\mathrm{cm}$ dish with a cover glass bottom (MatTek Corporation, Ashland, MA). Twenty four hours after seeding, cells were co-transfected with $1 \mu \mathrm{g}$ GFPTR $\alpha 1$ expression plasmid, and $1 \mu \mathrm{g}$ of the appropriate target-specific or control shRNA expression plasmids, using the two shRNAs from each set of four (see Section 2.1) that showed the greatest knockdown efficacy as assessed by quantitative PCR (see Section 2.4). Transfection medium containing Lipofectamine 2000 (Life Technologies) was replaced with complete medium $9 \mathrm{~h}$ post-transfection. Twenty seven hours post-transfection, cells were prepared for live-cell imaging: cells were incubated in 2 $\mathrm{mL}$ of complete media containing $100 \mu \mathrm{g} / \mathrm{mL}$ cycloheximide (Sigma-Aldrich, St. Louis, MO), 100 units $/ \mathrm{mL}$ penicillin, $100 \mu \mathrm{g} / \mathrm{mL}$ streptomycin, and $10 \mu \mathrm{g} / \mathrm{mL}$ wheat germ agglutinin conjugated to Alexa Fluor ${ }^{\circledR} 350$ (Life Technologies). Cells were washed twice with Dulbecco's phosphate-buffered saline and imaged. During the experiment, cells were incubated in MEM- $\alpha$ without phenol red, containing $50 \mu \mathrm{g} / \mathrm{mL}$ cycloheximide, 50 units $/ \mathrm{mL}$ penicillin, and $50 \mu \mathrm{g} / \mathrm{mL}$ streptomycin. In preliminary studies, we tested a range of post-transfection incubation times $(17 \mathrm{~h}, 24 \mathrm{~h}, 27 \mathrm{~h}$, and $30 \mathrm{~h})$, varied the amount of Lipofectamine 2000 and the time cells were exposed to the reagent, selected for knockdown cells with puromycin, and varied the shRNA plasmid amounts and combinations. The conditions described above were determined to have high transfection efficiency (70-80\% of cells were transfected), effectively reduce the levels of exportins in cells (at least 50\% knockdown), while still retaining cell viability. Altered conditions either decreased transfection efficiency, decreased knockdown efficiency, or led to increased cell mortality. Cell mortality was assessed by visual inspection of the number of adherent cells prior to transfection, compared with the number of cells remaining adhered post-transfection, with the standard set at $>60 \%$ retention.

All FRAP experiments were performed in an OkoLab Incubation System (Warner Instruments, Inc., Hamden, $\mathrm{CT}$ ) at $37^{\circ} \mathrm{C}$ under $5 \% \mathrm{CO}_{2}$. Images were collected from an inverted Nikon A1Rsi confocal microscope Ti-E-PFS using a 40X water objective (Nikon Inc., Melville, NY). The 488-nm line of a krypton-argon laser with a band-pass 525/50 nm emission filter was used for GFP detection; the 405-nm line with a band-pass 450/50 emission filter was used for Alexa Fluor ${ }^{\circledR} 350$ detection. Images were obtained using the stimulation/bleaching acquisition module of NIS-Elements AR (Nikon). An initial image was recorded from an area containing a GFP-expressing cell with two or more nuclei, using 1-4\% laser power from the $488 \mathrm{~nm}$ line and $8-20 \%$ laser power from the $405 \mathrm{~nm}$ line. One nucleus within the multinucleated cell was exposed at 100\% laser power for 10-12 sec using the $488 \mathrm{~nm}$ line. Post-bleach sequential images were then taken every 5 min for 24 cycles at the lower laser intensities noted above. For quantitative analysis of digitized images, fluorescent intensity values were generated using NISElements AR (Nikon). Bleached and unbleached nuclei were each considered as independent regions of interest. In addition, these values took into account the background brightness levels during each experiment. Intensity values were subsequently normalized so that the total fluorescence within each multinucleated cell after bleaching was equal to 1.0 (arbitrary units). After normalization, convergence of the representative curves for bleached and unbleached nuclei toward one another represents the degree of fluorescence equilibration between these compartments. When one bleached and one unbleached nucleus are present, complete equilibration occurs at 0.5 fluorescence units (Grespin et al., 2008). 


\subsection{Fixation, immunofluorescence, and cell scoring}

HeLa cells were seeded at 2.5-3.0 × $10^{5}$ cells per well of a 6-well plate with glass coverslips (Fisher Scientific, Pittsburgh, PA). Twenty four hours after seeding, cells were transfected with $2 \mu$ g plasmid DNA, using Lipofectamine 2000 Reagent. Approximately $18 \mathrm{~h}$ post-transfection, cells were fixed in 3.7\% formaldehyde and permeabilized with $0.2 \%$ Triton-X-100. The following antibodies were used at 1:500: anti-c-Myc (Clontech), Cy3-goat anti-mouse (Life Technologies/Zymed), and anti-HA tag (Abcam, Cambridge, MA). Texas Red anti-rabbit IgG $(\mathrm{H}+\mathrm{L})$ (Vector Laboratories, Burlingame, CA) antibody was used at 1:50. Coverslips were mounted in Fluoro-Gel II containing the DNA counter stain 4', 6diamidino-2'-phenylindole (DAPI, $0.5 \mu \mathrm{g} / \mathrm{ml}$ ) (Electron Microscopy Sciences, Hatfield, PA).

Images were analyzed with an inverted Nikon ECLIPSE TE 2000-E fluorescence microscope. A Nikon Ultraviolet Excitation: UV-2E/C filter block for DAPI visualization, a Blue Excitation: B-2E/C filter block for GFP, and a Red Excitation: T-2E/C filter block for the Myc or HA tag were used with a Nikon Plan Apo 40X objective. NIS-Elements AR software was used for image acquisition and primary image processing. Cells were scored blind, without knowledge of the treatment conditions. The slides' original labels were removed and replaced with random number labels by another lab member, who made a key and kept it secure until the scoring was completed and data were analyzed. All experiments consisted of a minimum of 3 replicates and at least 100-300 cells were scored per replicate. The state of the nuclei was assessed by visually examining the integrity and morphology of each DAPI-stained nucleus; only cells with intact nuclei were scored. Intracellular distribution patterns of TR in cells transfected with pGFP-TR $\alpha 1$ or pGFP-TR $\beta 1$ and pCMV-Myc or pMyc-Exp5 were scored into two categories: primarily nuclear $(\mathrm{N})$, or distributions ranging from nuclear accumulation but a clearly visible cytosolic population to a whole cell distribution $(\mathrm{N}+\mathrm{C} / \mathrm{WC})$. Intracellular distribution patterns of TR in cells transfected with pGFP-TR $\alpha 1$ or pGFP-TR $\beta 1$ and pmCherry-XPO4, pmCherry, pCMV-HA, or HAexportin 7 (RanBP16) plasmids were scored into three categories: primarily nuclear (N), nuclear accumulation and a clearly visible cytosolic population $(\mathrm{N}+\mathrm{C})$; or whole cell, where the nucleus was not distinct (WC) (see supplementary data Fig. S1). Data were quantified as the percentage of cells in a given category (e.g., \% of cells with a primarily nuclear distribution of TR).

\subsection{Validation of RNA interference (RNAi) by quantitative PCR (qPCR)}

HeLa cells seeded at 6-7 x 10 $0^{5}$ cells per 100-mm vented plate were transfected with $10 \mu \mathrm{g}$ targetspecific or control shRNA expression plasmids, using Lipofectamine 2000. Medium was replaced with complete medium $9 \mathrm{~h}$ post-transfection. Twenty seven hours post-transfection, RNA was extracted using the Aurum ${ }^{\mathrm{TM}}$ Total RNA Mini Kit (Bio-Rad, Hercules, CA) according to the manufacturer's specifications, with the exception that the DNase I digestion was extended to $30 \mathrm{~min}$. RNA quality was analyzed using an RNA 6000 Pico Total RNA Assay and Agilent 2100 BioAnalyzer's Lab-on-a-Chip Technology (Santa Clara, CA). cDNA was synthesized using the SABioscience RT ${ }^{2}$ First Strand Kit, following the manufacturer's specifications. Quantitative PCR (qPCR) was performed using the RealTime RT ${ }^{2}$ qPCR Primer Assay (SABiosciences) with $\mathrm{RT}^{2}$ Real-Time ${ }^{\mathrm{TM}}$ SYBR Green/Fluorescein qPCR master mix and SABioscience validated primers specific for each exportin, or glyceraldehyde-3phosphate dehydrogenase (GAPDH) as an internal control. qPCR data were analyzed by the $\Delta \Delta \mathrm{Ct}$ (Livak) method (Livak and Schmittgen, 2001) using the Applied Biosystems StepOne Software Version 2.1 (Life Technologies).

\subsection{Western blotting}

Twenty seven hours post-transfection, HeLa cells were harvested in lysis buffer (50 mM Hepes, $\mathrm{pH}$ 7.5, $150 \mathrm{mM} \mathrm{NaCl}, 10 \mathrm{mM} \mathrm{NaF}, 10 \%$ glycerol, 1\% Nonidet P-40 (Calbiochem, San Diego, CA), Complete Mini EDTA-free Protease Inhibitor Cocktail Tablet (1 tablet per $10 \mathrm{ml}$; Roche Diagnostics, 
Indianapolis, IN)). Lysates were centrifuged at $14,000 \mathrm{x}$ g for $10 \mathrm{~min}$ at $4^{\circ} \mathrm{C}$, and the supernatant protein concentration was determined using a NanoDrop ${ }^{\circledR}$ ND-1000 Full-spectrum UV/Vis Spectrophotometer. Lysates (40-60 $\mu \mathrm{g}$ of protein per lane) were separated by $8 \%$ SDS-PAGE and transferred to PVDF membrane using the iBlot Dry Blotting System (Life Technologies). The membranes were incubated overnight at $4^{\circ} \mathrm{C}$ in blocking solution (Tris-buffered saline containing $0.1 \%$ Tween 20 [T-TBS], $1 \%$ bovine serum albumin). After 4-6 washes with T-TBS at room temperature, the membranes were incubated with primary antibodies for 1.5-2 h. All antibodies were incubated separately and used at the following concentrations: anti- $\beta$-tubulin (Santa Cruz Biotechnology Inc., Dallas, TX), 1:200; antiexportin 5 (Abcam), 1:400; anti-transportin 1 (Abcam), $2.0 \mu \mathrm{g} / \mathrm{ml}$; anti-transportin 2 (Santa Cruz), 1:1000; anti-exportin 4 (Santa Cruz), 1:500; anti-exportin 5 (Santa Cruz), 1:1000; anti-exportin 7 (Abcam), $0.5 \mu \mathrm{g} / \mathrm{ml}$; and anti-GAPDH (Santa Cruz), 1:5000. Blots were then washed 4-6 times with TTBS and incubated with the appropriate secondary antibody for 1.25 hours in blocking solution. Secondary antibodies were used at the following concentrations: horseradish peroxidase (HRP)conjugated donkey anti-rabbit IgG (GE Healthcare Life Sciences, Pittsburgh, PA), 1:25,000; HRP-sheep anti-mouse IgG (GE Healthcare Life Sciences), 1:25,000; and HRP-mouse anti-goat IgG (Santa Cruz), 1:10,000 or 1:25,000. Subsequently, blots were washed 6-8 times in T-TBS, followed by chemiluminescent detection using ECL Prime detection reagent (GE Healthcare Life Sciences). Protein size was monitored using Pre-Stained Kaleidoscope Protein Standards (Bio-Rad). X-ray films were quantified by scanning densitometry using ImageJ software (National Institutes of Health, Bethesda, MD).

\subsection{Luciferase reporter gene assay}

HeLa cells were seeded at $2.0 \times 10^{4}$ per well in a 96-well plate (PerkinElmer, Waltham, MA). Seventeen hours after seeding, cells were transiently transfected with $100 \mathrm{ng}$ DNA, containing $25 \mathrm{ng}$ each of expression plasmids for GFP-TR $\alpha 1$ or GFP-TR $\beta 1$, TRE (DR+4)-firefly luciferase reporter, Renilla luciferase internal control, and mCherry, mCherry-XPO4, Myc, Myc-XPO5, HA, or HA-XPO7. Transfection medium was replaced with complete medium $6 \mathrm{~h}$ post-transfection. Twelve hours posttransfection, complete medium was replaced with $100 \mu$ MEM containing $10 \%$ charcoal-dextran stripped FBS (Life Technologies), supplemented or not with $100 \mathrm{nM} \mathrm{T}_{3}$. After an additional $12 \mathrm{~h}$, a Dual-Glo® Luciferase Assay (Promega) was performed, according to the manufacturer's protocol, using $100 \mu \mathrm{l}$ of reagent per well.

\subsection{Statistical analyses}

Data represent the mean \pm 1 SEM of at least three independent experiments. Statistical differences between two groups were determined using an unpaired Student's t test with the two-tailed $P$ value. Results were considered significant at $P<0.05$.

\section{Results}

\subsection{Knockdown of exportins 4, 5, and 7 slows nucleocytoplasmic shuttling of TR $\alpha 1$}

Prior studies pointed to the possibility that, in addition to following a cooperative CRM1/calreticulindependent export pathway during nucleocytoplasmic shuttling, TR may also follow an alternative nuclear export pathway that does not rely on CRM1 (Bunn et al., 2001; Grespin et al., 2008; Mavinakere et al., 2012). To determine whether other exportins play a role in mediating TR nuclear export, we coupled in vivo approaches using FRAP and RNAi in transfected HeLa cells to examine how knockdown of 
individual exportins impacts the shuttling dynamics of TR $\alpha 1$. Since TR $\alpha 1$ is primarily nuclear at steadystate, but shuttles between the nucleus and the cytosol, knockdown of an essential export factor would be predicted to result in decreased nuclear export of TR $\alpha 1$. This effect would be visualized as greater retention of fluorescence in the unbleached nucleus, along with a significantly slower recovery of fluorescence to the bleached nucleus during a FRAP assay. It is important to note, however, that it was not expected that cells would ever show complete inhibition of TR $\alpha 1$ shuttling since RNAi leaves a portion of the target mRNA and protein in cells, and there are likely multiple pathways for export. In addition, if knockdown of a bidirectional transport factor affected nuclear import instead, this defect in import would be visualized as an accumulation of TR $\alpha 1$ in the cytosol.

To begin, shRNA-induced knockdown of target exportin mRNA and protein levels were validated by qPCR and western blotting, respectively. The levels of exportin mRNA in the presence of target shRNA were reduced by $\geq 75 \%$, relative to the scrambled shRNA control (control mRNA expression was set at $100 \%$ ) (Fig. 1A). Exportin protein levels were reduced relative to the scrambled control, on average, as follows: transportin 1,31\%; transportin 2, 56\%; exportin 4, 41\%; exportin 5, 30\%; and exportin 7, 40\% (Fig. 1B). We were unable to acquire a viable antibody for exportin 6, so in this case validation was restricted to qPCR. Taken together, these levels of knockdown confirm the efficacy of the RNAi system.

Next, we compared shuttling of GFP-TR $\alpha 1$ with GFP-TR $\beta 1$ under standard conditions, in the absence of shRNA expression (Fig. 2A, supplementary data Videos S1 and S2). To confirm that experiments were conducted in a single cell with multiple nuclei and not nuclei in adjacent, separate cells, transfected HeLa cells were incubated before visualization with fluorescent-tagged wheat germ agglutinin (WGA), an external plasma membrane marker for live-cell imaging (Fig. 2A). All FRAP experiments were also performed in the presence of cycloheximide to ensure that the fluorescence recovery of GFP in bleached nuclei was not due to de novo protein synthesis. As shown in Fig. 2A, both TR $\alpha 1$ and TR $\beta 1$ undergo shuttling; however, for TR $\beta 1$ a faint cytosolic population is visible at $\mathrm{t}=0$, while $\mathrm{TR} \alpha 1$ appears entirely nuclear. Thus, to avoid any ambiguity in interpreting FRAP results, we only performed knockdown assays with TR $\alpha 1$. To determine the effect of exportin knockdown on the dynamic shuttling of TR $\alpha 1$, HeLa cells were cotransfected with GFP-TR $\alpha 1$ and exportin-specific shRNA expression plasmids.

We first tested whether transportins 1 and 2 play a role in TR $\alpha 1$ nuclear export (Fig. 2B). Originally proposed to mediate bidirectional transport, more recent studies maintain that transportins 1 and 2 are restricted to mediating nuclear import of RNA-binding proteins that function as splicing regulators (Twyffels et al., 2014). Therefore, we predicted that the transportins would not be involved in TR $\alpha 1$ shuttling. For quantitation of FRAP (Fig. 3), bleached and unbleached nuclei were each considered as independent regions of interest. Intensity values were normalized so that the total fluorescence within each multinucleated cell after bleaching was equal to 1.0 (arbitrary units). After normalization, convergence of the representative curves for bleached and unbleached nuclei toward one another represents the degree of fluorescence equilibration between these compartments. When one bleached and one unbleached nucleus are present, complete equilibration occurs at 0.5 fluorescence units (Grespin et al., 2008). Recovery of fluorescence to bleached nuclei within live cells transfected with a scrambled control shRNA was measured at, on average, 51\% fluorescence equilibration at $60 \mathrm{~min}$ and $72 \%$ at 120 min (Fig. 3). As expected, comparable shuttling dynamics were observed for cells transfected with transportin 1 shRNA, relative to the control (60 min, $P=0.89 ; 120 \mathrm{~min}, P=0.59$ ). At $60 \mathrm{~min}$ and $120 \mathrm{~min}$, transportin 1-knockdown cells showed, on average, $49 \%$ and $65 \%$ fluorescence equilibration with unbleached nuclei, respectively. Similarly, there was no significant difference in TR $\alpha 1$ shuttling between the control and transportin 2 shRNA-transfected cells ( $60 \mathrm{~min}, P=0.68 ; 120 \mathrm{~min}, P=0.78)$. At $60 \mathrm{~min}$ and $120 \mathrm{~min}$, transportin 2-knockdown cells showed, on average, $58 \%$ and $75 \%$ fluorescence equilibration with unbleached nuclei, respectively (Fig. 3). These data show that transportins 1 and 2 are not involved in nuclear retention or export of TR $\alpha 1$. Furthermore, no cytosolic accumulation of TR $\alpha 1$ was observed during the FRAP assay (Fig. 2B), indicating that knockdown of transportins 1 and 2 did not interfere with nuclear import of TR $\alpha 1$. 
Exportin 4 is a bidirectional nuclear transport factor involved in nuclear export of translation initiation factor eIF-5A and transcriptional regulator Smad3 (Chook and Suel, 2011). Thus, we predicted this selective transporter would not play a role in promoting TR $\alpha 1$ nuclear export. At $60 \mathrm{~min}$, there was no significant difference between TR $\alpha 1$ shuttling in control shRNA and exportin 4 shRNA-transfected cells (Figs. 2B and 3; supplementary data Videos S3 and S4) $(P=0.06)$, with recovery in bleached nuclei in knockdown cells measured at 34\% fluorescence equilibration, on average. However, unexpectedly, at 120 min there was a significant difference in the amount of recovery relative to the control $(P=0.04)$; exportin 4 knockdown-cells only reached 52\% fluorescence equilibration, on average (Fig. 3), suggesting that exportin 4 plays a role in TR nuclear export, either directly by facilitating exit of TR $\alpha 1$ from the nucleus or, indirectly by decreasing nuclear retention and thereby promoting interaction with other exportins. No cytosolic accumulation was observed (Fig. 2B), which if present would have been indicative of a defect in import, suggesting that exportin 4 does not play a role in mediating nuclear entry of TR $\alpha 1$.

The primary cargo of exportin 5 is microRNA (miRNA) precursors (Bohnsack et al., 2004; Lund et al., 2004); however, it also has been shown to mediate nuclear export of the androgen receptor, another member of the nuclear receptor superfamily (Shank et al., 2008). Thus, we predicted that knockdown of exportin 5 would alter TR $\alpha 1$ shuttling dynamics. Instead, although there appeared to be a modest decrease in TR $\alpha 1$ shuttling between cells transfected with control shRNA and exportin 5 shRNA knockdown, this effect was not significant at either $60 \mathrm{~min}(P=0.12)$ or $120 \mathrm{~min}(P=0.22)$ (Figs. 2B and 3). Fluorescence equilibration was measured, on average, at $38 \%$ and $60 \%$ for $60 \mathrm{~min}$ and $120 \mathrm{~min}$, respectively (Fig. 3). Since exportin 5 mediates export of pre-miRNA and shRNA from the nucleus, there is a trade-off between down-regulating exportin 5, but still getting enough pre-shRNA out of the nucleus for sustained knockdown of exportin 5 mRNA levels. Previously, it was shown that overexpressing exportin 5 in the presence of shRNA expression plasmids increased the efficiency of RNAi (Yi et al., 2005). Thus, we tested whether overexpressing exportin 5 in the presence of Myc-tagged exportin 5 shRNA could, albeit counterintuitively, enhance knockdown. First, we validated the utility of this approach. In the presence of XPO5 shRNA, exportin 5 protein levels were decreased compared to the control shRNA, where no knockdown occurred (Fig. 2C; see also Fig. 1B). In contrast, when exportin 5 is overexpressed, there was even greater knockdown of exportin 5 protein levels with target shRNA. After determining that more efficient knockdown occurs when overexpressing exportin 5, we ran parallel FRAP experiments. In comparison to the shRNA scrambled control, we observed a significant reduction in shuttling of TR $\alpha$ (Figs. 2B and 3, supplementary data Video S5) at $60 \mathrm{~min}(P=0.03)$; however, after 120 min recovery was not significantly different from the control $(P=0.05)$. The fluorescence equilbrations from unbleached nuclei to bleached nuclei were, on average, $26 \%$ at $60 \mathrm{~min}$ and $49 \%$ at $120 \mathrm{~min}$ (Fig. 3).

Next, we predicted that knockdown of exportins 6 and 7 would not alter TR $\alpha 1$ shuttling dynamics for the following reasons. Exportin 6 is a specific transporter of nuclear actin (Dopie et al., 2012; Stuven et al., 2003) and, although exportin 7 binds diverse cargo, it had not been shown to be involved in export of other members of the nuclear receptor superfamily (Mingot et al., 2004). As predicted, knockdown of exportin 6 resulted in similar TR $\alpha 1$ shuttling dynamics compared to the scrambled control, at both $60 \mathrm{~min}$ $(P=0.44)$ and $120 \mathrm{~min}(P=0.46)$ (Figs. 2B and 3). Fluorescent equilibration of bleached nuclei was measured, on average, at $43 \%$ and $63 \%$ for $60 \mathrm{~min}$ and $120 \mathrm{~min}$, respectively. In contrast, knockdown of exportin 7 resulted in altered shuttling of TR $\alpha 1$ (Figs. 2B and 3, supplementary data Video S6). Fluorescent equilibrations were measured, on average, at $32 \%$ and $48 \%$, for $60 \mathrm{~min}$ and $120 \mathrm{~min}$, respectively. Differences were not significant at $60 \mathrm{~min}(P=0.06)$; however, at $120 \mathrm{~min}$ there was a significant decrease in recovery $(P=0.03)$, compared with the control, suggesting that exportin 7 plays a role in TR $\alpha 1$ cellular localization, either directly via mediating nuclear export, or indirectly via increasing intranuclear mobility and access to the export machinery.

Finally, we predicted that dual knockdown with combinations of shRNA against exportins 4, 5, and 7 would have a greater impact than single knockdowns. However, when we tested dual knockdown of exportins 4 and 5, exportins 5 and 6 (as a control), and exportins 5 and 7, these combinations did not result in further shifts in the shuttling pattern of TR $\alpha 1$ (data not shown), although this could well be due 
to increased cell mortality. These exportins are required for trafficking of proteins involved in many vital cell processes and, since cellular miRNAs potentially regulate the expression of hundreds of genes, saturation of the RNAi pathway with exogenous shRNA also can contribute to loss of cell viability (Scherr and Eder, 2007; Castonotto and Rossi, 2009). In addition, it is likely that the primarily nuclear location of TR $\alpha 1$ at steady-state limits how much the shuttling pattern can be altered over the time course of an experiment.

Taken together, these data provide evidence that in addition to CRM1 and calreticulin, exportins 4, 5, and 7 either directly or indirectly play a role in promoting nuclear export of TR $\alpha 1$. In contrast, transportins 1 and 2, and exportin 6 do not play a role, or at least not an essential role, in modulating TR $\alpha 1$ shuttling.

\subsection{Overexpression of exportin 5 and exportin 7 promotes nuclear export of TR $\alpha 1$ and TR $\beta 1$}

Having shown that nucleocytoplasmic shuttling of TR $\alpha 1$ is partially inhibited by knockdown of exportins 4,5 , or 7 , we sought to ascertain whether their overexpression would alter the cellular localization of both TR $\alpha 1$ and TR $\beta 1$. We predicted that overexpression of exportins 4,5 , and 7 would cause a shift in the distribution of TR $\alpha 1$ and TR $\beta 1$, from the nucleus to the cytosol. To this end, HeLa cells were cotransfected with expression plasmids for GFP-tagged TR $\alpha 1$ or $\beta 1$, and mCherry-tagged exportin 4, Myc-tagged exportin 5, or HA-tagged exportin 7, or mCherry, Myc tag, or HA tag, as controls. Distribution patterns were visualized by direct fluorescence or immunofluorescence microscopy (Figs. 4 and 5).

Consistent with our predictions, when exportin 5 was overexpressed, a significantly greater percentage of cells showed a shift towards a more cytosolic distribution for both TR $\alpha 1(P=0.00001)$ and TR $\beta 1$ $(P=0.00006)$ (Fig. 4). In cells co-expressing GFP-TR $\alpha 1$ and the Myc tag (control), on average $90 \%$ of cells showed a primarily nuclear distribution of TR $\alpha 1$ (Fig. 4A). In contrast, in cells co-expressing GFPTR $\alpha 1$ and Myc-tagged exportin 5, on average only 52\% of cells showed a primarily nuclear distribution of TR $\alpha 1$ (Fig. 4A). In the cells expressing GFP-TR $\beta 1$ and the Myc tag, on average $76 \%$ of cells had a primarily nuclear distribution of TR $\beta 1$, compared with $34 \%$ of cells showing a primarily nuclear distribution of TR $\beta 1$ in the presence of Myc-tagged exportin 5 (Fig. 4B).

Interestingly, although knockdown of exportin 4 significantly slowed TR shuttling, overexpression of exportin 4 had no significant effect on the distribution patterns of either TR $\alpha 1(P=1.00)$ or TR $\beta 1(P=0.84)$ (Fig. 5A). In cells co-expressing GFP-TR $\alpha 1$ and mCherry (control) or mCherry-exportin 4, on average $77 \%$ of cells showed a nuclear localization of TR $\alpha 1$. In the cells co-expressing GFP-TR $\beta 1$ and mCherry or mCherry-exportin 4 , on average $55 \%$ of cells showed a nuclear localization of TR $\beta 1$.

Comparable results to exportin 5 were obtained when exportin 7 was overexpressed; a significantly greater percentage of cells showed a shift towards a more cytosolic distribution for both TR $\alpha 1$ and TR $\beta 1$, relative to the control $(P=0.00001)$ (Fig. 5B). In cells co-expressing GFP-TR $\alpha 1$ and the HA tag (control), on average $68 \%$ of cells showed a nuclear distribution of TR $\alpha 1$. In contrast, in cells co-expressing GFPTR $\alpha 1$ and HA-tagged exportin 7, on average only $25 \%$ of cells showed a primarily nuclear distribution of TR $\alpha 1$. In the cells expressing GFP-TR $\beta 1$ and the HA tag, on average $59 \%$ of cells had a primarily nuclear distribution of TR $\beta 1$, compared with $22 \%$ of cells showing a primarily nuclear distribution of TR $\beta 1$ in the presence of HA-exportin 7.

\subsection{Effect of enhanced nuclear export on TR-mediated ligand-independent and ligand-dependent gene expression}

In the absence of $T_{3}$, unliganded $T R \alpha 1$ and $T R \beta 1$ repress the expression of target genes that are under control of positive thyroid hormone response elements (TREs). In the presence of $T_{3}$, the liganded receptors stimulate expression of these same genes. Thus, we sought to ascertain whether the cytosolic 
shift in the distribution of TR $\alpha 1$ and TR $\beta 1$ resulting from overexpression of exportins 5 and 7 would alter TR-mediated gene expression to a comparable extent. A firefly luciferase reporter gene under the control of a positive TRE (DR+4) was used to examine ligand-dependent transactivation by TR $\alpha 1$ (Fig. 6A) and TR $\beta 1$ (Fig. 6B), in the presence of exportin 4 (no cytosolic shift), exportin 5, or exportin 7. Exportin overexpression was confirmed by western blot analysis (data not shown). In the absence of $\mathrm{T}_{3}$, for cells overexpressing mCherry-exportin 4 or Myc-exportin 5, there was no significant difference in relative luciferase activity by unliganded TR $\alpha 1$ or TR $\beta 1$, compared with luciferase activity in cells overexpressing mCherry and Myc controls (TR $\alpha 1+\mathrm{XPO} 4, P=0.29$; TR $\alpha 1+\mathrm{XPO}, P=0.07$; TR $\beta 1$ $+\mathrm{XPO} 4, P=0.36$; TR $\beta 1+\mathrm{XPO} 5, P=0.54$ ). Similarly, there was no significant difference in repression of luciferase activity by unliganded TR $\beta 1$ in cells overexpressing HA-exportin 7, compared to HA alone $(P=0.31)$ In contrast, cells overexpressing HA-exportin 7 showed significantly greater luciferase reporter activity in the presence of unliganded TR $\alpha 1$, compared with HA alone $(P=0.04)$. On average, luciferase activity levels were increased 3.0-fold in the presence of exogenous exportin 7, relative to levels in the absence of exogenous exportin 7, suggesting that exportin 7 has wider effects than on TR $\alpha 1$ export alone.

We also examined the ability of liganded TR to stimulate TRE-luciferase reporter gene expression. In the presence of $\mathrm{T}_{3}$, fold stimulation of luciferase activity by liganded TR $\alpha 1$ and TR $\beta 1$ in cells overexpressing Myc-exportin 5 or HA-exportin 7 was not significantly different compared with fold stimulation in the presence of the Myc and HA tag controls (TR $\alpha 1+\mathrm{XPO}$, $P=0.94$; TR $\alpha 1+\mathrm{XPO}$, $P=0.60$; TR $\beta 1+\mathrm{XPO} 5, P=0.41$; TR $\beta 1+\mathrm{XPO} 7, P=0.53$ ), indicating that under these conditions a reduction in the percentage of cells with primarily nuclear TR $\alpha 1$ or TR $\beta 1$ of $38-42 \%$ does not have a measurable impact on reporter gene stimulation. Likewise, fold stimulation by liganded TR $\beta 1$ in the presence of overexpressed mCherry-exportin 4 also was not significantly different from the control $(P=0.90)$. Interestingly, however, when TR $\alpha 1$ and mCherry-exportin 4 were co-expressed in the presence of $\mathrm{T}_{3}$, fold stimulation of luciferase was significantly increased, relative to mCherry alone $(P=0.01)$. On average, luciferase activity levels were increased 1.3-fold, relative to levels in the absence of exogenous exportin 4, suggesting that exportin 4 may interact with TR $\alpha 1$ in ways other than simply mediating nuclear transport.

\section{Discussion}

Previously we showed that TR $\alpha 1$ participates in rapid nucleocytoplasmic shuttling. Further, our results pointed to the intriguing possibility that, in addition to following a cooperative CRM1/calreticulindependent export pathway during nucleocytoplasmic shuttling, TR also follows an alternative nuclear export pathway that does not rely on CRM1 (Bunn et al., 2001; Grespin et al., 2008; Mavinakere et al., 2012). Here, we propose that additional exportins play a role in modulating TR cellular localization. By coupling in vivo RNAi and FRAP experiments, we showed that knockdown of exportins 4, 5, or 7 altered nucleocytoplasmic shuttling of TR $\alpha$ l. In addition, overexpression of exportins 5 and 7 shifted the distribution pattern of TR $\alpha 1$ and TR $\beta 1$ toward a greater percentage of cells with a more cytosolic distribution. Interestingly, results differed for TR $\alpha 1$ and TR $\beta 1$-mediated transactivation in cells expressing exogenous exportins. When TR $\beta 1$ and exportins 4, 5, or 7 were co-expressed, there was no significant change in either repression or stimulation of $\mathrm{T}_{3}$-mediated gene expression. In contrast, when exportin 7 was co-expressed with unliganded TR $\alpha 1$, TRE-luciferase reporter gene activity was significantly greater compared with the control; that is, in the presence of exportin 7 unliganded TR $\alpha 1$ was less able to repress transcription. In addition, when exportin 4 was co-expressed with liganded TR $\alpha 1$, fold stimulation of the TRE-luciferase reporter gene was significantly increased compared with the control. TR subtype-specific regulation of target gene expression is not without precedent; distinct properties of the amino terminus of TR $\alpha 1$ have been shown to lead to 2-fold greater ligand-independent repression and ligand-dependent stimulation (Hollenberg et al., 1995). Taken together, our data provide evidence that in addition to the previously characterized role of CRM1 and calreticulin in TR export, 
exportins 4, 5, and 7 also influence TR $\alpha 1$ and TR $\beta 1$ cellular localization either directly by promoting nuclear export, or indirectly by decreasing nuclear retention. In this way, exportin levels may provide an additional level of control in modulation of the cellular response to $\mathrm{T}_{3}$.

Further investigation will be required to determine why overexpression of exportin 4 had no significant effect on TR distribution, while knockdown markedly inhibited shuttling. No cytosolic accumulation of TR was observed, suggesting that reduced recovery of fluorescence in the bleached nucleus is not due to inhibition of nuclear import. It may be that levels of endogenous exportin 4 are high enough already to be saturating for export, or exportin 4 may interact with TR in ways other than simply mediating nuclear transport. Additional roles in the cell for exportin 4 beyond transport activity are becoming better understood. A recent report implicates exportin 4 as a tumor suppressor that is downregulated in hepatocellular carcinoma (Liang et al., 2011). In addition, exportin 4 plays a role in nuclear import of members of the Sox family of transcription factors (Gontan et al., 2009), and interacts directly with Sox 9, thereby blocking binding of Sox 9 to target genes (Tsuchiya et al., 2011). Here, we show that co-expressing exportin 4 with TR $\alpha 1$ increases ligand-dependent gene transactivation, but has no significant effect on ligand-independent repression. These data suggest that exportin 4 may exert its effects on TR localization indirectly, by altering nuclear retention and, thereby, promoting accessibility to the nuclear export machinery.

Recently, exportin 5 was shown to be important for mediating CRM1-independent nuclear export of the androgen receptor, through a NES located in the DNA binding and hinge domains of AR (Shank et al., 2008). Prior to this report, exportin 5 was only thought to be involved in regulating miRNA biogenesis by exporting the precursors of miRNAs out of the nucleus (Bohnsack et al., 2004; Lund et al., 2004; Yi et al., 2005). A role for exportin 5 in promoting nuclear export of TR $\alpha 1$ and TR $\beta 1$ further expands the potential cargo list for this versatile exportin. In addition to the cytosolic mislocalization of TR, since exportin 5 is critical for miRNA biogenesis, down-regulation of this exportin would be predicted to have widespread effects. More than 700 miRNAs have been identified in humans. With over two-thirds of protein-coding genes predicted as targets, these abundant small regulatory RNAs play important roles in modulating a broad range of cellular processes (Ebert and Sharp, 2012; Melo and Esteller, 2014). Indeed, inactivating mutations in exportin 5, and the concomitant trapping of pre-miRNA in the nucleus, are linked to human tumors with microsatellite instability, including colon, gastric, and endometrial tumors (Melo et al., 2010).

We conclude that exportin 7 is also a player in regulating shuttling of TR $\alpha 1$ and TR $\beta 1$. Exportin 7 (also known as RanBP16) mediates export of diverse proteins with variable NESs including eIF4A1, p50RhoGAP, 14-3-3 $\sigma$ (Mingot et al., 2004), and histones during erythroid maturation (Hattangadi et al., 2014). Intriguingly, despite promoting a significant cytosolic shift in the distribution pattern of TR, overexpression of exportin 7 had no significant effect on ligand-dependent stimulation; however, overexpression of exportin 7 did result in a significant increase in activity of a TRE-linked reporter gene by unliganded TR $\alpha 1$, suggesting less potent repressor activity. These findings suggest that exportin 7 overexpression has an impact on other factors that play a role in $\mathrm{T}_{3}$-independent gene regulation. TR does not act alone; the receptor requires association with coactivators to enhance transcription, and corepressors to silence transcription. In this way, TR activity can be modulated by the balance between coactivator and corepressor activity (Soriano et al., 2011). It may be that less potent TR $\alpha 1$-mediated reporter gene repression when exportin 7 is overexpressed in the absence of $\mathrm{T}_{3}$ reflects more rapid export of a corepressor. Interestingly, exportin 7 mediates nuclear export of liver kinase B1 (LKB1) (Liang et al., 2015). Cytosolic activated LKB1 is a "master kinase" that controls at least 13 downstream AMP-activated protein kinase (AMPK)-related kinases, and acts as a tumor suppressor (Dupuy et al., 2013; Gan and Li, 2014). Further, $T_{3}$ has been shown to increase LKB1 expression in muscle, resulting in activation of LKB1/AMPK signalling pathway, and an increase in levels of peroxisome proliferator-activated receptor$\gamma$ coactivator-1 $\alpha$ (PGC-1 $\alpha$ ) (Branvold et al., 2008). PGC-1 $\alpha$ enhances gene expression mediated by TR, while the silencing mediator of retinoic acid and thyroid hormone receptors (SMRT) represses gene 
expression. Although not linked to LKB1 levels, nuclear export of SMRT has been shown to be triggered by changes in cell activity (Guo et al., 2013; Soriano et al., 2011). It is tempting to speculate that exportin 7-promoted nuclear exit of LKB1 initiates a cascade of events, culminating in upregulation of TR $\alpha 1$ coactivators and downregulation of corepressors.

The results presented here highlight the complexity of TR shuttling, and provide further evidence of a role for multiple exportins in promoting nuclear export of this nuclear receptor, either through direct interactions or indirect mechanisms. Comprehensive analysis of how nuclear export integrates with other signaling pathways should help to identify the interacting partners in the fine balance of TR nuclear import, retention, and export. In addition, characterization of protein-protein interactions by in vitro and in vivo binding assays will clarify which of the exportins serve as a direct carrier for each of the multiple NES motifs in TR $\alpha 1$ and TR $\beta 1$, and will enhance understanding of how multiple pathways coordinate nuclear exit in response to cell-specific signals.

\section{Acknowlegements}

This work was supported in part by National Institutes of Health grant 2R15DK058028-03 and National Science Foundation grant MCB 1120513 (to L.A.A.).

\section{References}

Arts, G.J., Fornerod, M., and Mattaj, I.W. (1998). Identification of a nuclear export receptor for tRNA. Curr Biol 8, 305-314.

Baumann, C.T., Maruvada, P., Hager, G.L., and Yen, P.M. (2001). Nuclear cytoplasmic shuttling by thyroid hormone receptors - Multiple protein interactions are required for nuclear retention. J Biol Chem 276, 11237-11245.

Black, B.E., Vitto, M.J., Gioeli, D., Spencer, A., Afshar, N., Conaway, M.R., Weber, M.J., and Paschal, B.M. (2004). Transient, ligand-dependent arrest of the androgen receptor in subnuclear foci alters phosphorylation and coactivator interactions. Mol Endocrinol 18, 834-850.

Bohnsack, M.T., Czaplinski, K., and Gorlich, D. (2004). Exportin 5 is a RanGTP-dependent dsRNAbinding protein that mediates nuclear export of pre-miRNAs. RNA 10, 185-191.

Branvold, D.J., Allred, D.R., Beckstead, D.J., Kim, H.J., Fillmore, N., Condon, B.M., Brown, J.D., Sudweeks, S.N., Thomson, D.M., and Winder, W.W. (2008). Thyroid hormone effects on LKB1, MO25, phospho-AMPK, phospho-CREB, and PGC-1 $\alpha$ in rat muscle. J Appl Physiol (1985) 105, 1218-1227.

Bunn, C.F., Neidig, J.A., Freidinger, K.E., Stankiewicz, T.A., Weaver, B.S., McGrew, J., and Allison, L.A. (2001). Nucleocytoplasmic shuttling of the thyroid hormone receptor $\alpha$. Mol Endocrinol 15, 512533.

Castanotto, D., and Rossi, J.J. (2009) The promises and pitfalls of RNA-interference-based therapeutics. Nature 457, 426-433,

Chook, Y.M., and Suel, K.E. (2011). Nuclear import by karyopherin- $\beta$ s: recognition and inhibition. Biochim Biophys Acta 1813, 1593-1606.

DeLong, L.J., Bonamy, G.M., Fink, E.N., and Allison, L.A. (2004). Nuclear export of the oncoprotein vErbA is mediated by acquisition of a viral nuclear export sequence. J Biol Chem 279, 15356-15367.

Dopie, J., Skarp, K.P., Rajakyla, E.K., Tanhuanpaa, K., and Vartiainen, M.K. (2012). Active maintenance of nuclear actin by importin 9 supports transcription. Proc Natl Acad Sci U S A 109, E544-552.

Dupuy, F., Griss, T., Blagih, J., Bridon, G., Avizonis, D., Ling, C., Dong, Z., Siwak, D.R., Annis, M.G., Mills, G.B., Muller, W.J., Siegel, P.M., Jones, R.G. (2013). LKB1 is a central regulator of tumor initiation and pro-growth metabolism in ErbB2-mediated breast cancer. Cancer Metab 1, 18.

Ebert, M.S., and Sharp, P.A. (2012). Roles for microRNAs in conferring robustness to biological processes. Cell 149, 515-524. 
Gan, R.Y., and Li, H.B. (2014). Recent progress on Liver Kinase B1 (LKB1): Expression, regulation, downstream signaling and cancer suppressive function. Int J Mol Sci 15, 16698-16718.

Gontan, C., Guttler, T., Engelen, E., Demmers, J., Fornerod, M., Grosveld, F.G., Tibboel, D., Gorlich, D., Poot, R.A., and Rottier, R.J. (2009). Exportin 4 mediates a novel nuclear import pathway for Sox family transcription factors. J Cell Biol 185, 27-34.

Grespin, M.E., Bonamy, G.M.C., Roggero, V.R., Cameron, N.G., Adam, L.E., Atchison, A.P., Fratto, V.M., and Allison, L.A. (2008). Thyroid hormone receptor $\alpha 1$ follows a cooperative CRM1/calreticulin-mediated nuclear export pathway. J Biol Chem 283, 25576-25588.

Guo, L., Chen, C., Liang, Q., Karim, M.Z., Gorska, M.M., and Alam, R. (2013). Nuclear translocation of MEK1 triggers a complex $\mathrm{T}$ cell response through the corepressor silencing mediator of retinoid and thyroid hormone receptor. J Immunol 190, 159-167.

Hattangadi, S.M., Martinez-Morilla, S., Patterson, H.C., Shi, J., Burke, K., Avila-Figueroa, A., Venkatesan, S., Wang, J., Paulsen, K., Gorlich, D., Murata-Hori, M., Lodish, H.F. (2014). Histones to the cytosol: Exportin 7 is essential for normal terminal erythroid nuclear maturation. Blood.

Holaska, J.M., Black, B.E., Rastinejad, F., and Paschal, B.M. (2002). $\mathrm{Ca}^{2+}$-dependent nuclear export mediated by calreticulin. Mol. Cell. Biol. 22, 6286-6297.

Hollenberg, A.N., Monden, T., Wondisford, F.E. (1995). Ligand-independent and -dependent functions of thyroid hormone receptor isoforms depend upon their distinct amino termini. J. Biol. Chem. 270, 14274-14280.

Kanno, Y., Suzuki, M., Miyazaki, Y., Matsuzaki, M., Nakahama, T., Kurose, K., Sawada, J., and Inouye, Y. (2007). Difference in nucleocytoplasmic shuttling sequences of rat and human constitutive active/androstane receptor. Biochim Biophys Acta 1773, 934-944.

Kanno, Y., Suzuki, M., Nakahama, T., and Inouye, Y. (2005). Characterization of nuclear localization signals and cytoplasmic retention region in the nuclear receptor CAR. Biochim Biophys Acta 1745, 215-222.

Kimura, M., and Imamoto, N. (2014). Biological significance of the importin- $\beta$ family-dependent nucleocytoplasmic transport pathways. Traffic 15, 727-748.

Koch, P., Bohlmann, I., Schafer, M., Hansen-Hagge, T.E., Kiyoi, H., Wilda, M., Hameister, H., Bartram, C.R., and Janssen, J.W. (2000). Identification of a novel putative Ran-binding protein and its close homologue. Biochem Biophys Res Commun 278, 241-249.

Kutay, U., Bischoff, F.R., Kostka, S., Kraft, R., and Gorlich, D. (1997). Export of importin $\alpha$ from the nucleus is mediated by a specific nuclear transport factor. Cell 90, 1061-1071.

Kutay, U., Hartmann, E., Treichel, N., Calado, A., Carmo-Fonseca, M., Prehn, S., Kraft, R., Gorlich, D., and Bischoff, F.R. (2000). Identification of two novel RanGTP-binding proteins belonging to the importin $\beta$ superfamily. J Biol Chem 275, 40163-40168.

Liang, H.J., Chai, R.C., Li, X., Kong, J.G., Jiang, J.H., Ma, J., Vatcher, G., and Yu, A.C. (2015). Astrocytic exportin-7 responds to ischemia through mediating LKB1 translocation from the nucleus to the cytoplasm. J Neurosci Res. 93, 253-67

Liang, X.T., Pan, K., Chen, M.S., Li, J.J., Wang, H., Zhao, J.J., Sun, J.C., Chen, Y.B., Ma, H.Q., Wang, Q.J., Xia, J.C. (2011). Decreased expression of XPO4 is associated with poor prognosis in hepatocellular carcinoma. J Gastroenterol Hepatol 26, 544-549.

Liu, J., and DeFranco, D.B. (2000). Protracted nuclear export of glucocorticoid receptor limits its turnover and does not require the exportin 1/CRM1-directed nuclear export pathway. Mol Endocrinol $14,40-51$.

Livak, K.J., and Schmittgen, T.D. (2001). Analysis of relative gene expression data using real-time quantitative PCR and the $2^{-{ }^{-\Delta \Delta} C \mathrm{~T}}$ method. Methods 25, 402-408.

Lombardi, M., Castoria, G., Migliaccio, A., Barone, M.V., Di Stasio, R., Ciociola, A., Bottero, D., Yamaguchi, H., Appella, E., and Auricchio, F. (2008). Hormone-dependent nuclear export of estradiol receptor and DNA synthesis in breast cancer cells. J Cell Biol 182, 327-340. 
Lund, E., Guttinger, S., Calado, A., Dahlberg, J.E., and Kutay, U. (2004). Nuclear export of microRNA precursors. Science 303, 95-98.

Mavinakere, M.S., Powers, J.M., Subramanian, K.S., Roggero, V.R., and Allison, L.A. (2012). Multiple novel signals mediate thyroid hormone receptor nuclear import and export. J Biol Chem 287, 31280 31297.

Melo, S.A., and Esteller, M. (2014). Disruption of microRNA nuclear transport in human cancer. Semin Cancer Biol 27, 46-51.

Melo, S.A., Moutinho, C., Ropero, S., Calin, G.A., Rossi, S., Spizzo, R., Fernandez, A.F., Davalos, V., Villanueva, A., Montoya, G., Yamamoto, H., Schwartz, S. Jr., Esteller, M. (2010). A genetic defect in exportin-5 traps precursor microRNAs in the nucleus of cancer cells. Cancer Cell 18, 303-315.

Mingot, J.M., Bohnsack, M.T., Jakle, U., and Gorlich, D. (2004). Exportin 7 defines a novel general nuclear export pathway. EMBO J 23, 3227-3236.

Nguyen, M.M., Dincer, Z., Wade, J.R., Alur, M., Michalak, M., Defranco, D.B., and Wang, Z. (2009). Cytoplasmic localization of the androgen receptor is independent of calreticulin. Mol Cell Endocrinol 302, 65-72.

Pemberton, L.F., and Paschal, B.M. (2005). Mechanisms of receptor-mediated nuclear import and nuclear export. Traffic 6, 187-198.

Picard, D., and Yamamoto, K.R. (1987). Two signals mediate hormone-dependent nuclear localization of the glucocorticoid receptor. EMBO J 6, 3333-3340.

Saporita, A.J., Zhang, Q., Navai, N., Dincer, Z., Hahn, J., Cai, X., and Wang, Z. (2003). Identification and characterization of a ligand-regulated nuclear export signal in androgen receptor. J Biol Chem 278, 41998-42005.

Scherr, M., and Eder, M. (2007) Gene silencing by small regulatory RNAs in mammalian cells. Cell Cycle 6, 444-449.

Shank, L.C., Kelley, J.B., Gioeli, D., Yang, C.S., Spencer, A., Allison, L.A., and Paschal, B.M. (2008). Activation of the DNA-dependent protein kinase stimulates nuclear export of the androgen receptor in vitro. J Biol Chem 283, 10568-10580.

Soriano, F.X., Leveille, F., Papadia, S., Bell, K.F.S., Puddifoot, C., and Hardingham, G.E. (2011). Neuronal activity controls the antagonistic balance between peroxisome proliferator-activated receptor- $\gamma$ coactivator- $1 \alpha$ and silencing mediator of retinoic acid and thyroid hormone receptors in regulating antioxidant defenses. Antiox Redox Signal 14, 1425-1436.

Sorokin, A., Kim, E., and Ovchinnikov, L. (2007). Nucleocytoplasmic transport of proteins. Biochem (Moscow) 72, 1439-1457.

Stuven, T., Hartmann, E., and Gorlich, D. (2003). Exportin 6: a novel nuclear export receptor that is specific for profilin.actin complexes. EMBO J 22, 5928-5940.

Tsuchiya, M., Ogawa, H., Suzuki, T., Sugiyama, N., Haraguchi, T., and Hiraoka, Y. (2011). Exportin 4 interacts with Sox9 through the HMG Box and inhibits the DNA binding of Sox9. PLoS One 6, e25694.

Twyffels, L., Gueydan, C., and Kruys, V. (2014). Transportin-1 and Transportin-2: protein nuclear import and beyond. FEBS Lett 588, 1857-1868.

Umemoto, T., and Fujiki, Y. (2012). Ligand-dependent nucleo-cytoplasmic shuttling of peroxisome proliferator-activated receptors, PPAR $\alpha$ and PPAR $\gamma$. Genes Cells 17, 576-596.

Yi, R., Doehle, B.P., Qin, Y., Macara, I.G., and Cullen, B.R. (2005). Overexpression of exportin 5 enhances RNA interference mediated by short hairpin RNAs and microRNAs. RNA 11, 220-226. 


\section{Figure Legends}

Fig. 1. Validation of shRNA knockdown of target gene mRNA and protein levels. (A) HeLa cells were transiently transfected with a panel of exportin-specific shRNA expression plasmids, as indicated, or a scrambled shRNA plasmid as a control. qPCR was used to confirm knockdown of exportin mRNA levels. Bars indicate the relative expression level of exportin mRNA in cells treated with exportin-specific shRNA versus control cells (control mRNA expression set at 100\%), normalized to the levels of the housekeeping mRNA, GAPDH. Error bars indicate \pm 1 SEM $(n=3)$. TNPO1, transportin 1; TNPO2, transportin 2; XPO4, exportin 4; XPO5, exportin 5; XPO6, exportin 6; XPO7, exportin 7. (B) Western blot analysis was used to confirm knockdown of exportin protein levels relative to the control (control protein expression set at 100\%), as indicated. Error bars indicate \pm 1 SEM ( $\mathrm{n}=3, \mathrm{TNPO} 1, \mathrm{XPO} 4, \mathrm{XPO}$, $\mathrm{XPO} 7 \mathrm{n}=5$, TNPO2).

Fig. 2. FRAP analysis of TR shuttling after knockdown of export factors. (A) HeLa cells were transiently transfected with expressions plasmids for GFP-TR $\alpha 1$ or GFP-TR $\beta 1$, as indicated. Two Quick-Time movie files are attached as supplemental materials (Videos S1 and S2). FRAP experiments were performed in multinucleated live cells to monitor the movement of GFP-tagged TR $\alpha 1$ or TR $\beta 1$ from unbleached to bleached nuclei. To identify cells with two or more nuclei, cells were treated with Alexa Fluor ${ }^{\circledR}$ 350-tagged wheat germ agglutinin (WGA), a plasma membrane marker. Representative images are shown pre-bleach and $0 \mathrm{~min}, 60 \mathrm{~min}$, and $120 \mathrm{~min}$ post-bleach. (B) HeLa cells were transiently transfected with GFP-TR $\alpha 1$, scrambled shRNA control $(n=7)$, or shRNA expression plasmids targeting transportin $1(\mathrm{TNPO} 1, \mathrm{n}=6)$, transportin $2(\mathrm{TNPO} 2, \mathrm{n}=6)$, exportin $4(\mathrm{XPO} 4, \mathrm{n}=7)$, exportin 5 (XPO5, $\mathrm{n}=9$ ), exportin 6 (XPO6, n=7), or exportin 7 (XPO7, n=10). Alternatively, cells were cotransfected with GFP-TR $\alpha 1$ and Myc-exportin 5 (Myc-XPO5) expression plasmids, along with exportin 5 shRNA (n=4). Quick-Time movie files are attached as supplemental materials for the scrambled shRNA control and for exportins 4, 5, and 7 shRNA knockdown (Videos S3-S6). (C) HeLa cells were transiently transfected with GFP-TR $\alpha 1$ expression plasmid, Myc-tagged exportin 5 (Myc-XPO5) expression plasmid, Myc expression plasmid as a control, and shRNA expression plasmid targeting exportin 5 (XPO5 shRNA), or scrambled shRNA control. Cell lysates were subject to western blot analysis using antibodies specific for exportin 5 and $\beta$-tubulin as a loading control.

Fig. 3. Nucleocytoplasmic shuttling of TR $\alpha 1$ is slowed by knockdown of exportins 4, 5, and exportin 7 . Fluorescence recovery graphs summarize the data from the replicate FRAP experiments described in Fig. 2B. Blue squares are the intensity within bleached nuclei and red diamonds are the intensity within unbleached nuclei. Intensity values were normalized so that the total fluorescence within each multinucleated cell after bleaching was equal to 1.0 (arbitrary units). Convergence of the curves for bleached and unbleached nuclei toward one another represents the degree of fluorescence equilibration between the nuclei. When one bleached and one unbleached nucleus are present, complete equilibration occurs at 0.5 fluorescence units. Error bars indicate \pm 1 SEM. ${ }^{*} P<0.05$.

Fig. 4. Overexpression of exportin 5 promotes nuclear export of TR $\alpha 1$ and TR $\beta 1$. (A) HeLa cells were transiently transfected with GFP-TR $\alpha 1$ expression plasmids, Myc or Myc-XPO5 (exportin 5), as indicated. Cells were immunostained with anti-Myc (red) and analyzed by fluorescence microscopy for the distribution of TR $\alpha 1$ (green). Nuclei were stained for DNA with DAPI (blue). Bar graph summarizes the effect of overexpressing exportin 5 on TR $\alpha 1$ distribution in two categories: primarily nuclear $(\mathrm{N})$, or distribution patterns ranging from nuclear accumulation and a clearly visible cytosolic population to a whole cell distribution $(\mathrm{N}+\mathrm{C} / \mathrm{WC})$. Error bars represent \pm 1 SEM $(\mathrm{n}=4$ replicates each, with at least 300 cells scored per replicate). ${ }^{* * *} P<0.001$. (B) Parallel experiments were performed with HeLa cells 
cotransfected with GFP-TR $\beta 1$ expression plasmid and Myc or Myc-XPO5 ( $\mathrm{n}=4$ replicates, 100-300 cells per replicate).

Fig. 5. Overexpression of exportin 7 promotes nuclear export of TR $\alpha 1$ and TR $\beta 1$. (A) HeLa cells were transiently transfected with GFP-TR $\alpha 1$ or GFP-TR $\beta 1$, and mCherry or mCherry-tagged exportin 4 (XPO4) expression plasmids, as indicated. Bar graph summarizes the lack of effect of exportin 4 overexpression on TR distribution in three categories: primarily nuclear $(\mathrm{N})$, nuclear accumulation and a clearly visible cytosolic population $(\mathrm{N}+\mathrm{C})$; or whole cell, where the nucleus was not distinct (WC). Error bars represent \pm 1 SEM ( $n=3$ replicates, 100-300 cells scored per replicate). (B) Bar graph summarizing experiments performed with HeLa cells co-transfected with GFP-TR $\alpha 1$ or GFP-TR $\beta 1$, and HA tag or HA-tagged exportin 7 (XPO7) expression plasmids, as indicated. Error bars indicate \pm 1 SEM ( $\mathrm{n}=5$ replicates, $100-300$ cells per replicate). $* * * P<0.001$.

Fig. 6. Overexpression of exportins 4, 5, and 7 has variable effects on TR-mediated ligand-independent and ligand-dependent gene regulation. (A) HeLa cells were transfected with GFP-TR $\alpha$, mCherry or mCherry-exportin 4 (mCh-XPO4), Myc or Myc-exportin 5 (Myc-XPO5), or with HA or HA-exportin 7 (HA-XPO7) expression plasmids, and TRE (DR+4)-firefly luciferase reporter and Renilla luciferase internal control. Data are presented as relative ligand-independent luciferase reporter activity (firefly/Renilla) $\left(-\mathrm{T}_{3}\right)$, and fold stimulation in the presence of $\mathrm{T}_{3}$. Error bars indicate \pm 1 SEM $(\mathrm{n}=3$ replicates of 8 wells per treatment); ${ }^{*} P<0.05$, ${ }^{*} P<<0.01$. (B) Parallel experiments with GFP-TR $\beta 1$ ( $\mathrm{n}=4$ replicates). 
A

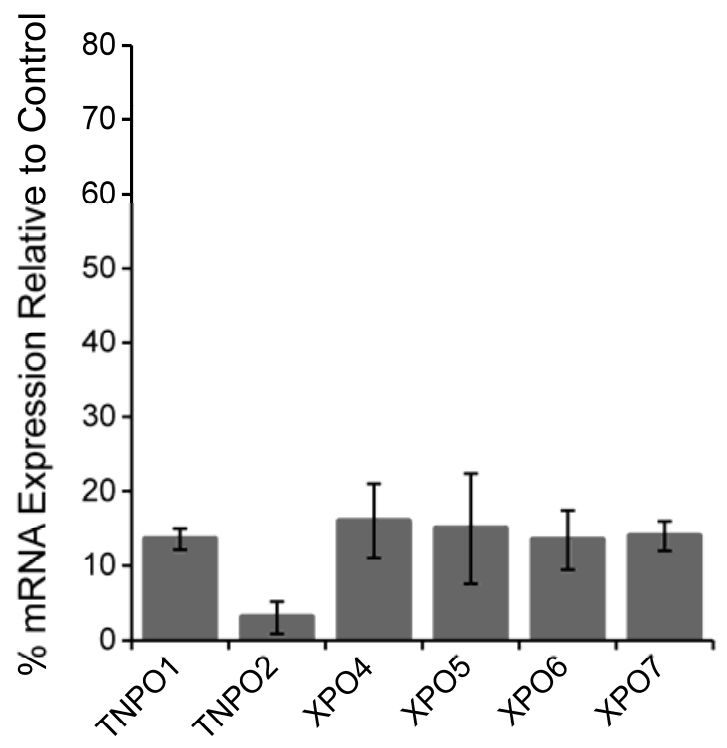

Figure 1.
B
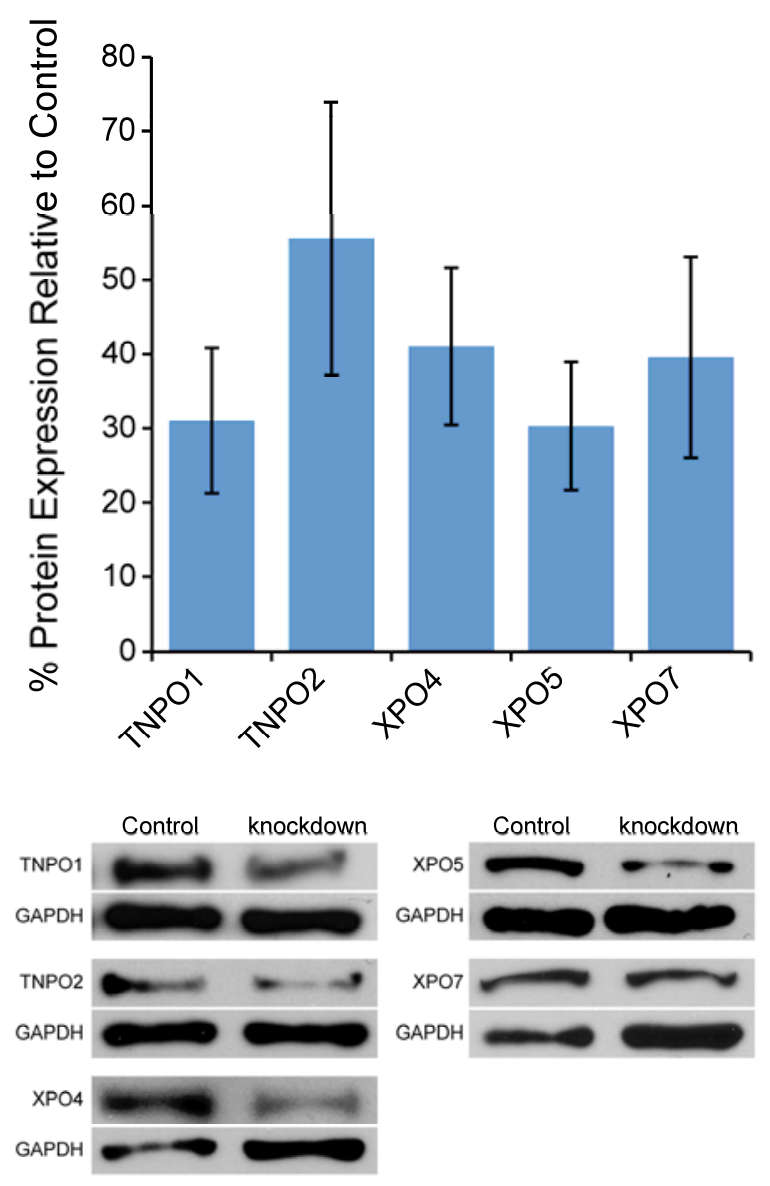


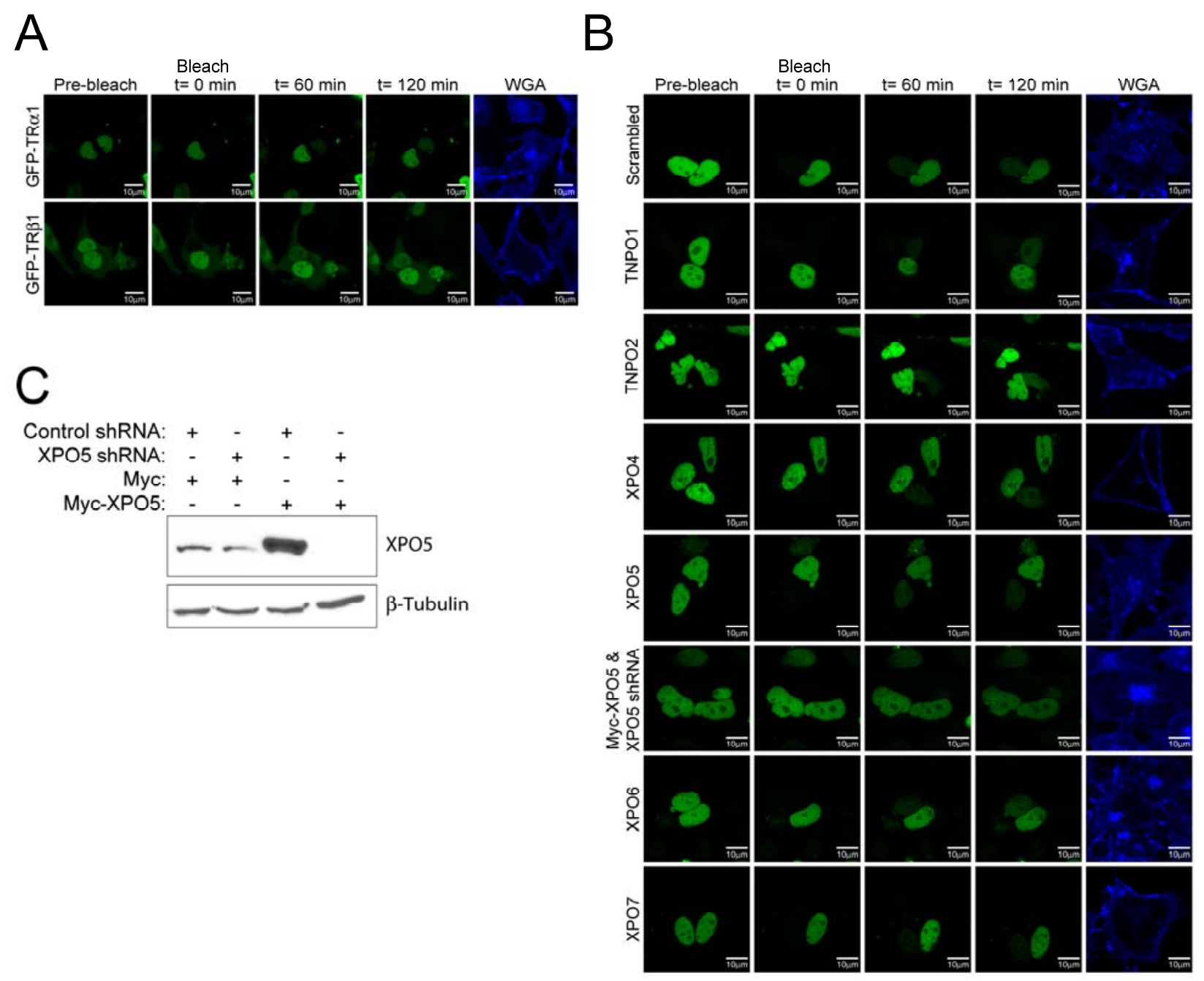

Figure 2. 

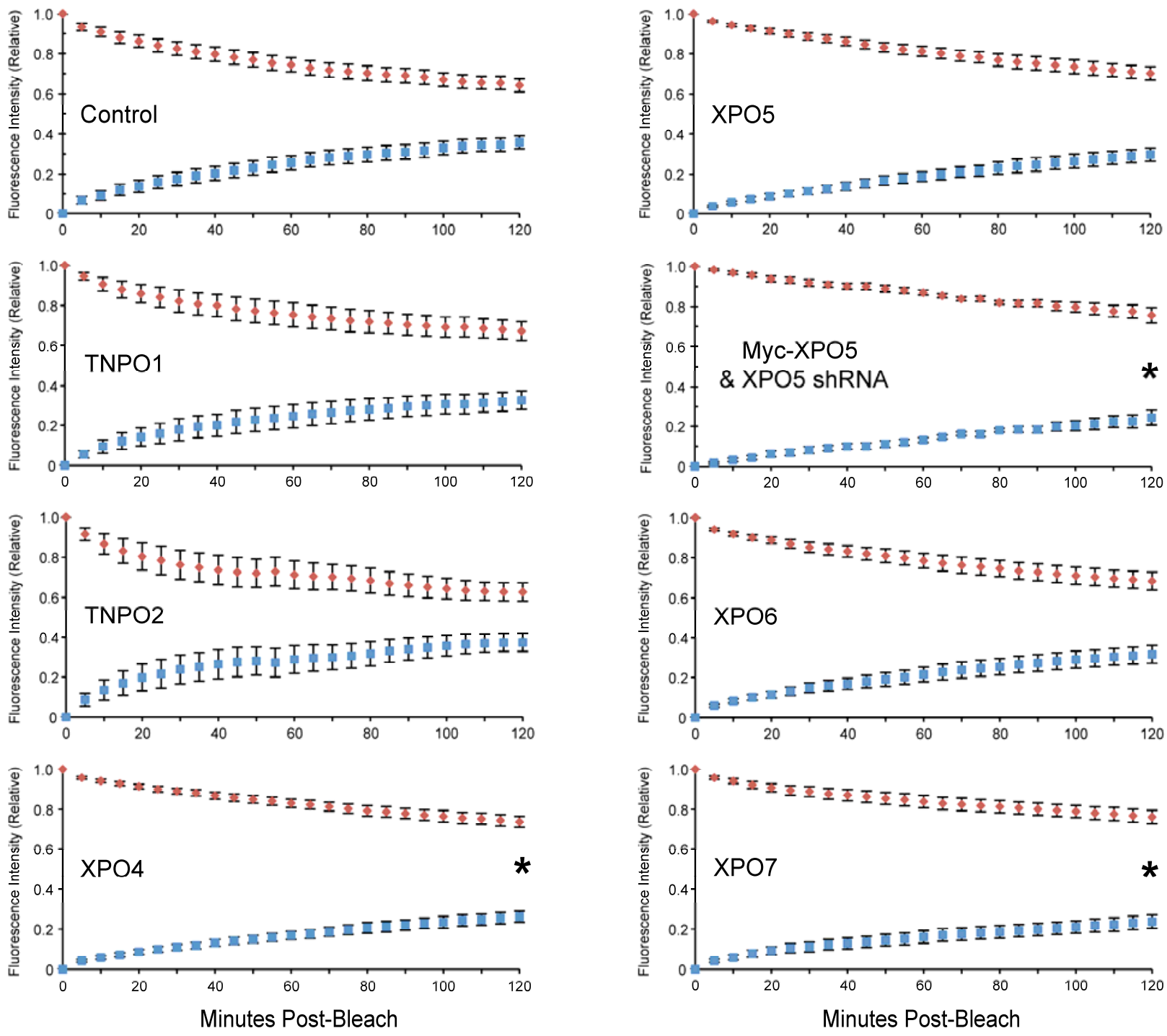

Figure 3. 
A
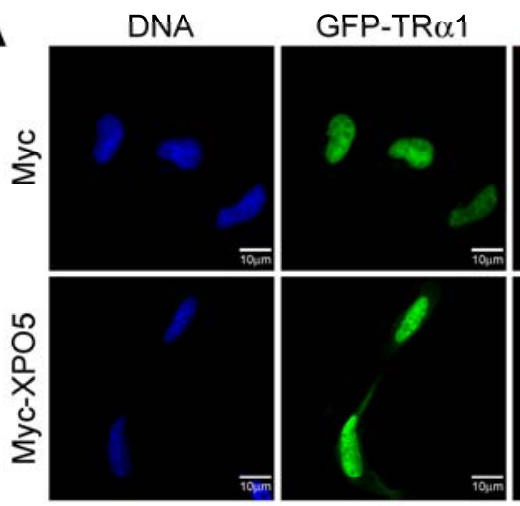

B

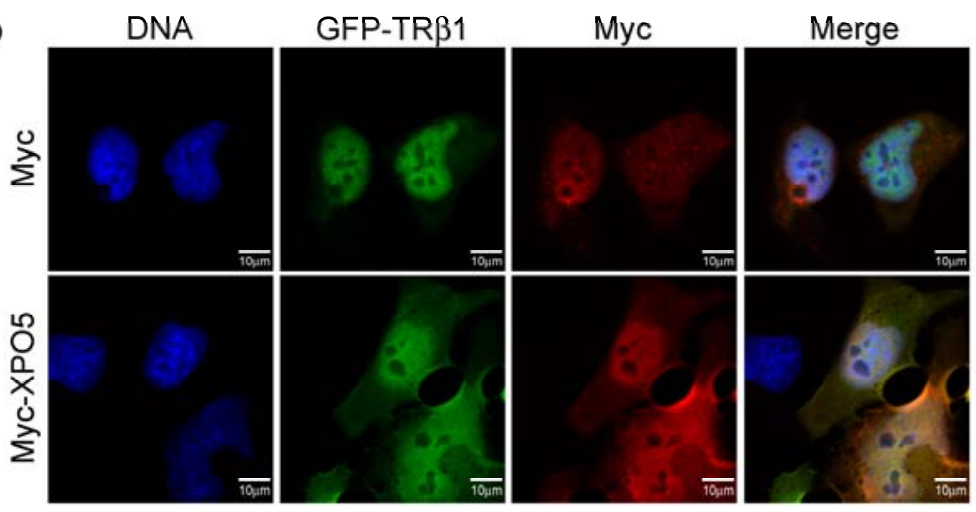

Merge
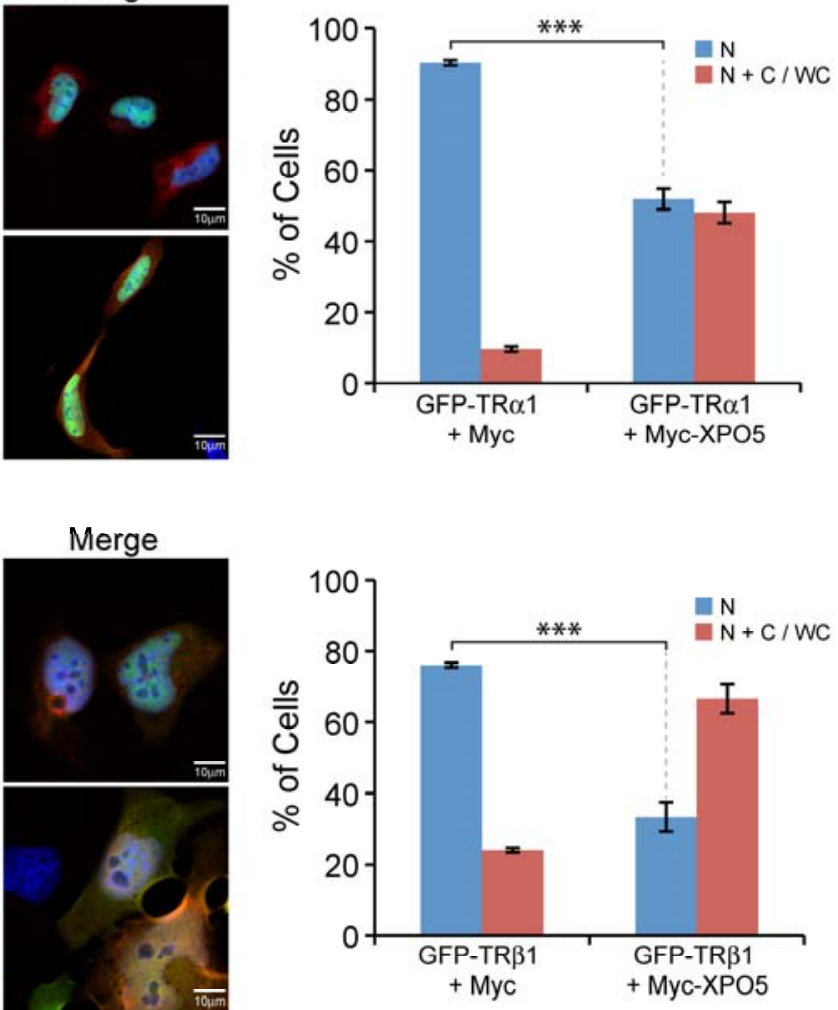

Figure 4 . 


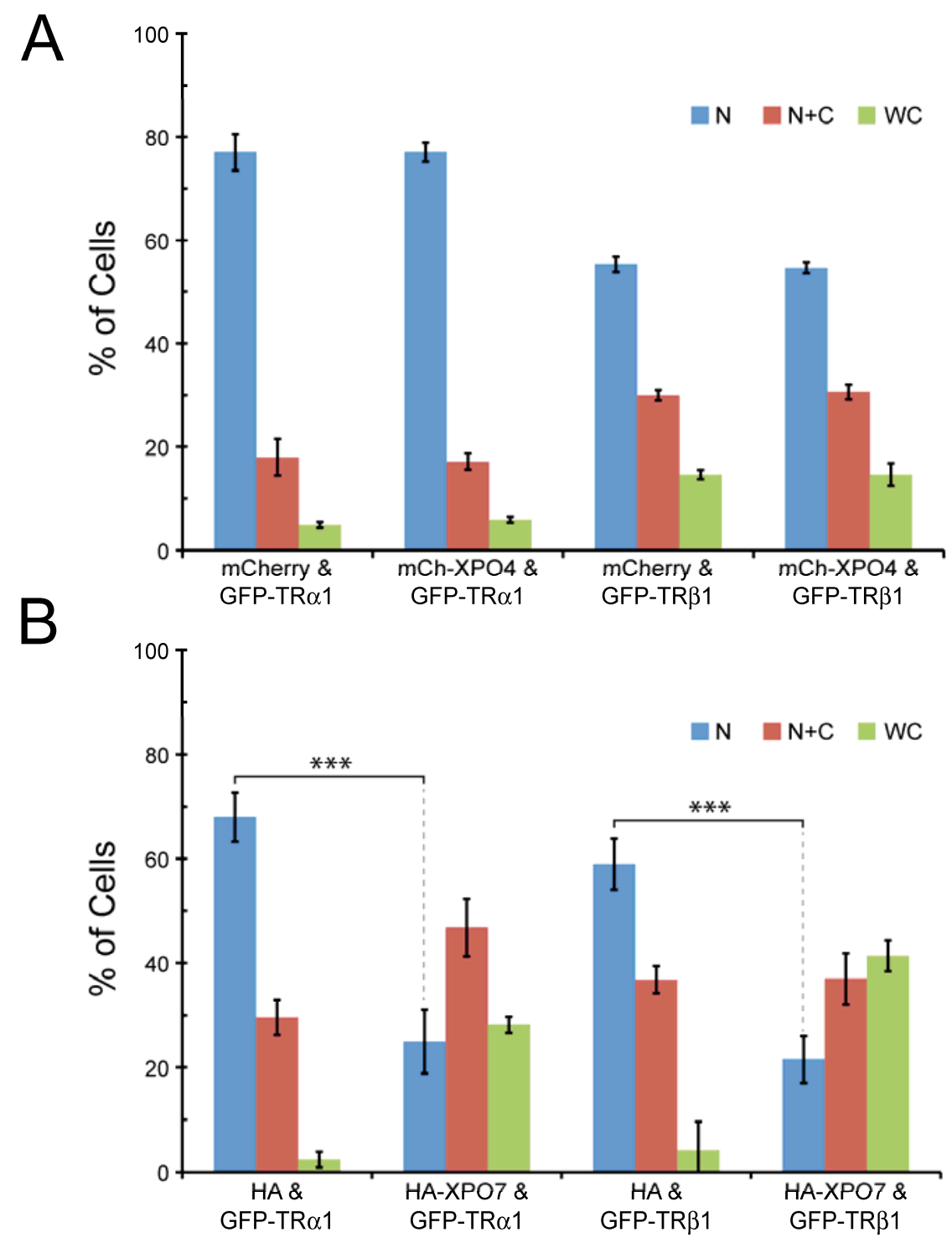

Figure 5. 

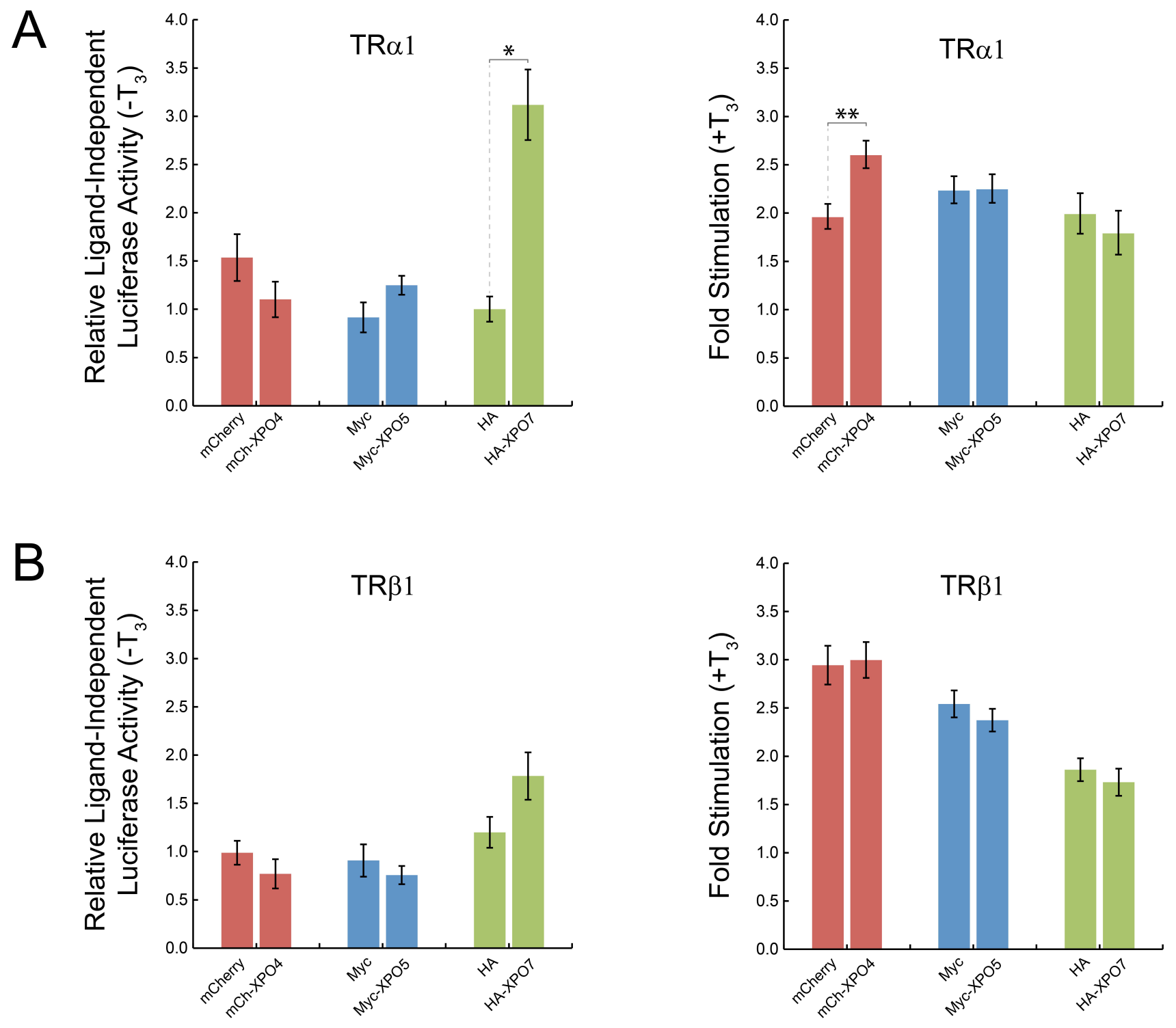

Figure 6. 